\title{
Prevalence of Celiac Disease Autoimmunity in Ethiopian Pregnant Women: A Cross Sectional Study from the Oromia region
}

\author{
Adugna Negussie Gudeta ${ }^{1}$, Charlotte Brundin ${ }^{1}$, Daba Muleta Feyissa ${ }^{2}$, Taye Tolera Balcha ${ }^{3}$, Daniel Agardh ${ }^{1,4, *}$ \\ ${ }^{1}$ Department of Clinical Sciences, Lund University, Malmo, Sweden \\ ${ }^{2}$ Adama Public Health Research \& Referral Laboratory Center, Adama, Ethiopia \\ ${ }^{3}$ Armauer Hansen Research Institute, Addis Ababa, Ethiopia \\ ${ }^{4}$ Department of Pediatrics, Skåne University Hospital in Malmö-Lund \\ *Corresponding author: daniel.agardh@med.lu.se
}

Received July 20, 2019; Revised September 02, 2019; Accepted December 04, 2019

\begin{abstract}
Celiac disease is a chronic small bowel disease induced by ingestion of gluten in genetically susceptible individuals affecting $1 \%$ among Caucasians in the Western world. The prevalence of celiac disease is still unknown in most developing countries, especially in Africa which suffer from lack of resources to perform screening of the general population. The aim of this study was to determine the prevalence of celiac disease autoimmunity in women undergoing antenatal care in selected Ethiopian health institutes. A total of 1942 pregnant women were included at median 25 (range 15-45) years of age who were attending antenatal care at 14 health centers of Central and South-East Oromia regional state of Ethiopia. Serum samples were analyzed for both IgA and IgG autoantibodies against tissue transglutaminase (tTG) using radioligand binding assays. Celiac disease autoimmunity defined as testing positive for both of IgA-tTG and IgG-tTG. In all, 4 of $1942(0.2 \%)$ were positive for IgG-tTG of whom one participant $(0.05 \%)$ was positive for both IgA-tTG and IgG-tTG and defined as having celiac disease autoimmunity. Based on these results, it was concluded that celiac disease autoimmunity is expected to be less common among the female adult Ethiopian population compared with the expected prevalence in Caucasians.
\end{abstract}

Keywords: autoantibodies, celiac disease, Ethiopia, gluten, teff, tissue transglutaminase

Cite This Article: Adugna Negussie Gudeta, Charlotte Brundin, Daba Muleta Feyissa, Taye Tolera Balcha, and Daniel Agardh, "Prevalence of Celiac Disease Autoimmunity in Ethiopian Pregnant Women: A Cross Sectional Study from the Oromia region.” International Journal of Celiac Disease, vol. 7, no. 3 (2019): 74-77. doi: 10.12691/ijcd-7-3-1.

\section{Introduction}

Celiac disease is a common autoimmune disease affecting the small bowel caused by a lifelong intolerance to ingested gluten in genetic susceptible individuals carrying the HLA-DQ2 and DQ8 risk haplotypes [1]. The etiology is most likely multifactorial caused by both genetic and environmental factors [2]. The clinical presentation of celiac disease is wide ranging from virtually clinically silent forms to diarrhea and severe malabsorption syndrome [3]. In fact, the majority of cases with celiac disease will only be detected by active case finding [2,4], and therefore most patients are expected to remain undiagnosed in many countries. The prevalence of celiac disease range from $0.0-2.9 \%$ in the Western world [5-9], but screening studies on the general population are still warranted from many countries around the globe in order to estimate the true prevalence of the disease.

Celiac disease is strongly associated with autoantibodies against tissue transglutaminase (tTG) and having persistently circulating tTG autoantibodies is coined celiac disease autoimmunity (CDA) [10]. Screening of populations for celiac disease using tTG autoantibodies enables detection of undiagnosed cases with subclinical or silent forms [11,12]. Celiac disease is particularly common in Scandinavia [13], but other countries are now reporting an emerging increase in incidence $[14,15]$. This difference in prevalence is diverse and most likely attributed to genetics, diet and exposures to environmental factors, but also access to diagnostic facilities or performed screenings in the general population. For instance, celiac disease is more common in populations with a high prevalence of HLA-DQ2 and DQ8 haplotypes and a high consumption of gluten-containing foods $[16,17]$. However, the prevalence in most parts of the world is still unrecorded due to lack of access to serology tests. Despite HLA-DQ2 and DQ8 haplotypes are frequent among populations in North African, celiac disease is still considered to be rare [18]. Ethiopia is with its about 100 million habitants the second most populated country after Nigeria in Africa constituting of people of multiethnic origin $[19,20]$. From a celiac disease point of view, Ethiopia 
is interesting for several reasons. Firstly, approximately $20 \%$ of the population carry any of the HLA risk haplotypes [9], but celiac disease is considered to be rare [21]. Secondly, wheat, teff, barely, maize and sorghum are the main cereal staples used as food sources, but the export of teff is increasing as a popular a gluten-free crop whereas consumption of wheat is increasing in Ethiopia [19,22,23,24]. Thirdly, and maybe more importantly, no study has yet screened for celiac disease in the general population in Ethiopia.

The main aim of the present study was to determine the prevalence of CDA in pregnant women attending antenatal care at various health institutes of Ethiopia by screening for tTG autoantibodies.

\section{Materials and Methods}

\subsection{Study Population}

The Oromia region is situated in the Central and Southeastern parts of Ethiopia (Figure 1) and is the largest regional state with near to 40 million inhabitants [25]. In 2017, 5000 pregnant women participated in national syphilis sentinel surveillance from 10 health institutes of Central and Southeast Oromia region of whom biological specimen were collected and stored in the repository at the Adama Public Health Research and Referral Laboratory in Oromia, Ethiopia. Adama Public Health Research and Referral Laboratory Center was established by Oromia Health Bureau with the support of Center of Disease Control (CDC)-Ethiopia to conduct health related operational research, identification of etiological agents during outbreak investigation and participate on intervention, provide advanced laboratory diagnostic service and capacity building of health facility laboratories [26].

After the study was approved by National Ethical Review Board of Ethiopia, Armauer Hansen Research institute and Adama Research and Public Health Laboratory, a total of 2000 pregnant women were randomly selected of whom samples with complete data were available from 1942.

\subsection{Methods}

Serum samples were kept at $-20^{\circ} \mathrm{C}$ freezer and shipped to Clinical Research Center (CRC) at Lund University in Malmö, Sweden, for analysis of IgA-tTG and IgG-tTG in separate assays as previously described $[10,12]$. In short, ${ }^{35} \mathrm{~S}$ labelled tTG were produced by coupled transcription/translation system using the TNT® Coupled Reticulocyte Lysate an in vitro single-tube system in the laboratory. An agarose tTG antigen-antibody complex was coated with anti-human IgA for binding IgA-tTG. A protein A sepharose (PAS) coated with anti-human IgG was used for binding IgG-tTG as previously described (Zymed Laboratories, Inc., San Francisco, CA, USA). Using QQ-plots, a cut off value of $4.0 \mathrm{U} / \mathrm{ml}$ or above considered as IgA-tTG and IgG-tTG positive, respectively, representing 99\% percentile of normal. Serum samples were not tested for IgA-deficiency.

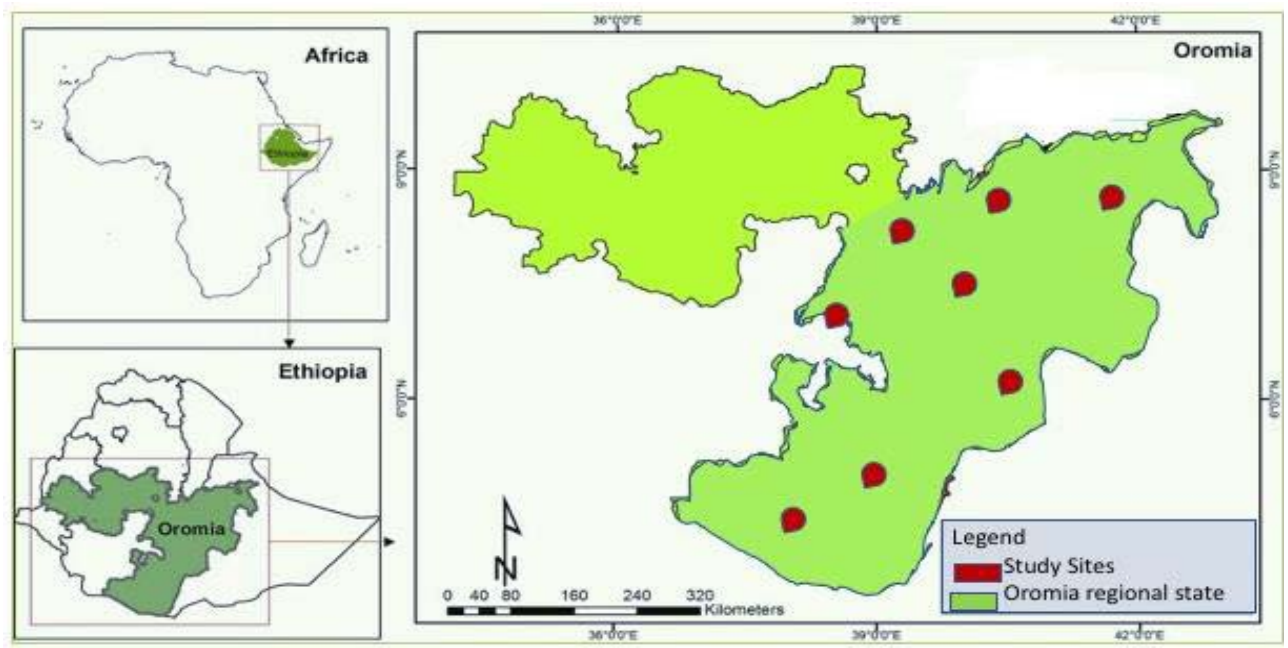

Figure 1. Geographic location of study districts of Oromia regional state in Ethiopia (Map source: [27])

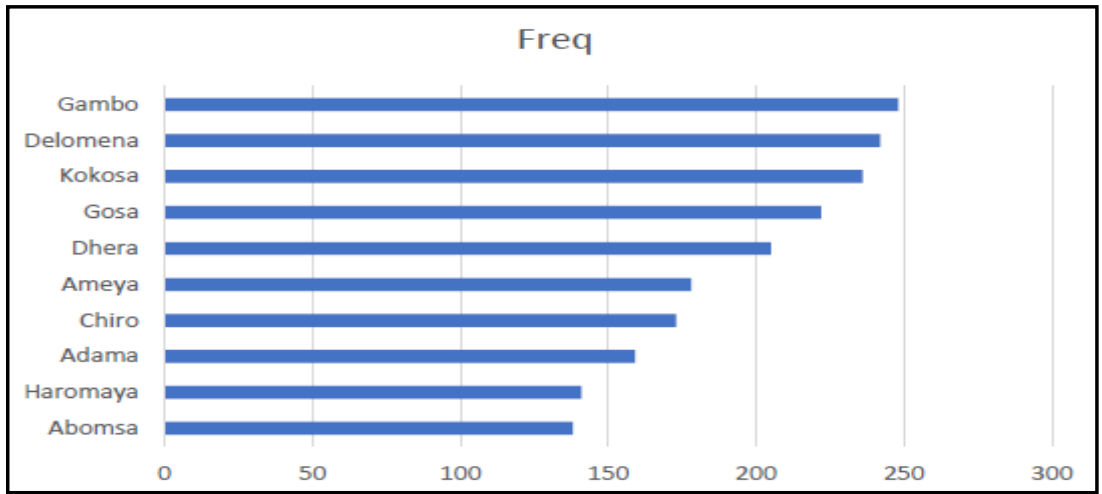

Figure 2. Frequency of Study participants by study sites 


\section{Results}

Data were abstracted proportional from the study sites and of the study participants the most were recruited from Gambo followed by Delomena health center (Figure 2). Available were 1942 of 2000 serum samples with completed information from the 2000 women and analyzed for both IgA-tTG and IgG-tTG. Median age of study population were 25 (range 15-45) years of age (Table 1). Median levels of study population were 0.182 (range 0-196.4) U/mL for IgA-tTG and 0.894 (range 0-257.6) U/mL for IgG-tTG, respectively. Of the screened 1942 women, one (0.05\%) was positive for IgA-tTG, another four $(0.2 \%)$ were positive for IgG-tTG and among those only one $(0.05 \%)$ was defined as having CDA (Table 2).

Table 1. Demographics of the study population $(n=1942)$

\begin{tabular}{|c|c|c|}
\hline Characteristic & Group & Frequency (\%) \\
\hline \multirow{7}{*}{ Age } & $15-19$ & 267 (13.7) \\
\hline & $20-24$ & 654 (33.7) \\
\hline & $25-29$ & 614 (31.6) \\
\hline & $30-34$ & 270 (13.9) \\
\hline & $35-39$ & $116(6.0)$ \\
\hline & $\geq 40$ & $16(0.8)$ \\
\hline & Missing & $5(0.3)$ \\
\hline \multirow[t]{2}{*}{ Maternal Residence } & Rural & 1471(75.7) \\
\hline & Urban & $471(24.3)$ \\
\hline \multirow{9}{*}{ Parity } & 0 & $516(26.6$ \\
\hline & 1 & $458(23.6)$ \\
\hline & 2 & $303(15.6)$ \\
\hline & 3 & $220(11.3)$ \\
\hline & 4 & $166(8.5)$ \\
\hline & 5 & $116(6.0)$ \\
\hline & $\geq 6$ & $161(8.4)$ \\
\hline & Missing & $2(0.1)$ \\
\hline & Total & $1942(100)$ \\
\hline
\end{tabular}

Table 2. Characteristics of IgA-tTG and IgG-tTG positive women

\begin{tabular}{|c|c|c|c|c|c|}
\hline Participant & $\begin{array}{c}\text { Age in } \\
\text { years }\end{array}$ & Resident & Parity & $\begin{array}{c}\text { IgA-tTG } \\
\text { (U/ml) }\end{array}$ & $\begin{array}{c}\text { IgG-tTG } \\
\text { (U/ml) }\end{array}$ \\
\hline$\# 1$ & 20 & rural & 1 & 196.4 & 257.6 \\
\hline$\# 2$ & 15 & rural & 0 & Negative & 49.3 \\
\hline$\# 3$ & 29 & rural & 4 & Negative & 27.9 \\
\hline$\# 4$ & 28 & urban & 0 & Negative & 8.8 \\
\hline$\# 5$ & 18 & rural & 0 & 9.40 & Negative \\
\hline
\end{tabular}

\section{Discussion}

This is the first study to estimate the prevalence of CDA in an adult female Ethiopian population. We screened 1942 pregnant women at a median 25 years of age for CDA and found only $0.05 \%$ of the Ethiopian pregnant women to have CDA, which is less prevalent as compared to other population based screenings from Europe and from the United States of America [28,29,30,31]. Our findings are consistent with the prevalence of CDA in some countries report in the world, but when comparing the proportion of celiac disease in pregnant women the prevalence is much lower compared with other developed countries [32].
The differences in prevalence of CDA are most likely multifactorial and attributed to heterogeneity in multi-ethnicity of the Ethiopian population as well as differences in exposures to environmental factors involving diet and infectious microbes. Recently, the TEDDY showed that children at genetic risk reporting a high intake of gluten amounts during the first 5 years of life are at increased risk of developing celiac disease [33]. In Ethiopia, the traditional food is gluten free and based on teff as the major grain. This might explain the the low prevalence of CDA found in this study, and potentially explain why celiac disease, is considered less common in Ethiopia as compared to population studies performed on Caucasians.

Using samples from pregnant women randomly selected from the population is a strength and minimize the risk of selection bias. Using radiobinding assays to assess tTG autoantibodies with proven high diagnostic sensitivity and specificity for celiac disease [8,12,34,35]. Moreover, radioligand binding assays have been used in several previous prospective screening studies for celiac disease [8,35] and proven the best performance as compared to other ELISAs in an international tTG workshop [36]. In various previous studies, it was demonstrated that the serum IgG level is decreased during pregnancy since it cross placenta to prevent the fetus $[37,38]$. However, by analyzing IgA-tTG as well as IgGtTG separately we feel confident that being positive in both assays is a good proxy for CDA.

The study has several limitations. First, it may not show the true prevalence of CDA in the Ethiopian population as it targets only pregnant women. Second, the study population was from the Central and Southeastern parts of Ethiopia and we did not perform HLA genotyping. Ethiopia is one of the most multiethnic second populated countries in Africa and there are differences in genetics as well as the use of food sources and feeding culture between ethnic groups. Therefore, we can only speculate that the study population is representative for the region, albeit the distribution of HLA genotypes was unknown. However, HLA genotyping from a previous study from the same country showed that the prevalence of HLA risk genotypes were estimated at 20\% [9].

In conclusion, this study indicated that celiac disease in Ethiopian women is rare compared with the expected prevalence among Caucasians. The reason for this discrepancy is still unresolved, but proposed to be attributed to difference in both genetic factors and intake of traditional Ethiopian food based on teff. Screening studies on younger generations of Ethiopian children bred on wheat products are warranted in order to the reveal if celiac disease is an emerging disease as in other parts of the developing world.

\section{Author Contributions}

DA, AN, CA, PN and TT designed the research project conception, developed the overall research plan; $\mathrm{AN}$ and $\mathrm{CB}$ performed the laboratory analysis of the data and performed the statistical analysis; AN and DA: wrote the manuscript and had primary responsibility for the final content, DM participate on study subject and related data abstracting. 


\section{Funding}

This study has been financially supported by Swedish Research Council, Swedish Celiac Disease Foundation, Håkanssons Stiftelse and Pålssons Stiftelse.

\section{References}

[1] Guandalini S, Assiri A. Celiac disease: a review. JAMA Pediatr. 2014; 168(3): 272-8.

[2] Lionetti E, Catassi C. The Role of Environmental Factors in the Development of Celiac Disease: What Is New? Diseases. 2015; 3(4): 282-93.

[3] Ludvigsson JF, Leffler DA, Bai JC, Biagi F, Fasano A, Green PH, et al. The Oslo definitions for coeliac disease and related terms. Gut. 2013; 62(1): 43-52.

[4] Catassi C, Gatti S, Fasano A. The new epidemiology of celiac disease. J Pediatr Gastroenterol Nutr. 2014; 59 Suppl 1: S7-9.

[5] Ludvigsson JF, Green PH. Clinical management of coeliac disease. J Intern Med. 2011; 269(6): 560-71.

[6] Rebecca Hancock, Koren G. Celiac disease during pregnancy. Canadian Family Physician. 2004; 50.

[7] Rubio-Tapia A, Kyle RA, Kaplan EL, Johnson DR, Page W, Erdtmann F, et al. Increased prevalence and mortality in undiagnosed celiac disease. Gastroenterology. 2009; 137(1): 88-93.

[8] Tiboni GM, de Vita MG, Faricelli R, Giampietro F, Liberati M. Serological testing for celiac disease in women undergoing assisted reproduction techniques. Hum Reprod. 2006; 21(2): 376-9.

[9] Gujral N. Celiac disease: Prevalence, diagnosis, pathogenesis and treatment. World Journal of Gastroenterology. 2012; 18(42).

[10] Daniel Agardh, Ingrid Dahlbom, Terri Daniels, Ester Lörinc, Sten Anders Ivarsson, $\mathrm{A}^{\circ} \mathrm{ke}$ Lernmark, et al. Autoantibodies Against Soluble and Immobilized Human Recombinant Tissue Transglutaminase in Children with Celiac Disease. Journal of Pediatric Gastroenterology and Nutrition. 2005; 41(322-327).

[11] Lebwohl B, Rubio-Tapia A, Assiri A, Newland C, Guandalini S. Diagnosis of celiac disease. Gastrointest Endosc Clin N Am. 2012; 22(4): 661-77.

[12] Hideyuki Nakazawa, Hideki Makishima, Toshiro Ito, Hiroyoshi Ota, Kayoko Momose, Nodoka, et al. Screening Tests Using Serum Tissue Transglutaminase IgA May Facilitate the Identification of Undiagnosed Celiac Disease among Japanese Population. Int J Med Sci. 2014; 11.

[13] Gebremariam MM, Zarnkow M, Becker T. Teff (Eragrostis tef) as a raw material for malting, brewing and manufacturing of gluten-free foods and beverages: a review. Journal of food science and technology. 2014; 51(11): 2881-95.

[14] Makharia GK, Verma AK, Amarchand R, Bhatnagar S, Das P, Goswami A, et al. Prevalence of celiac disease in the northern part of India: a community based study. J Gastroenterol Hepatol. 2011; 26(5): 894-900.

[15] Theresa Wan-Chen Yap W-KC, Alex Hwong-Ruey Leow, Ahmad Najib Azmi, Mun-Fai Loke, Jamuna Vadivelu, Khean-Lee Goh. Prevalence of Serum Celiac Antibodies in a Multiracial Asian Population-A First Study in the Young Asian Adult Population of Malaysia. PLOS ONE. 2015.

[16] Lucila Arantes CECILIO, BONATTO MW. THE PREVALENCE OF HLA DQ2 AND DQ8 IN PATIENTS WITH CELIAC DISEASE, IN FAMILY AND IN GENERAL POPULATION. ABCD Arq Bras Cir Dig. 2015; 28(3): 183-5.

[17] Amendola LM, Berg JS, Horowitz CR, Angelo F, Bensen JT, Biesecker BB, et al. The Clinical Sequencing Evidence-Generating Research Consortium: Integrating Genomic Sequencing in Diverse and Medically Underserved Populations. Am J Hum Genet. 2018; 103(3): 319-27.

[18] Barada K, Bitar A, Mokadem MA, Hashash JG, Green P. Celiac disease in Middle Eastern and North African countries: a new burden? World J Gastroenterol. 2010; 16(12): 1449-57.
[19] Mekuria W. The link between agricultural production and population dynamics in Ethiopia: a review. Advances in Plants \& Agriculture Research. 2018; 8(4).

[20] Nations ECfAU. The Demographic Profile of African Countries. Addis Ababa (C) UN ECA. 2016; 3.

[21] Habtamu A, Kebede T. Celiac Disease, A Rare Cause Of Malabsorption Syndrome In Children; The First Case Report In An Ethiopian Children. Ethiop Med J,. 2018; 56(2).

[22] Baye K. Teff: nutrient composition and health benefits. The Ethiopia Strategy Support Program Research Note. 2014.

[23] Mezemir S. PROBIOTIC POTENTIAL AND NUTRITIONAL IMPORTANCE OF TEFF (Eragrostis tef (Zucc) Trotter) ENJERRA - A review. African Journal of Food, Agriculture, Nutrition and Development. 2015; 15(2).

[24] Guush Berhane, Zelekawork Paulos, Kibrom Tafere, Tamru S. Foodgrain Consumption and Calorie Intake Patterns in Ethiopia. IFPRI Ethiopia Strategy Support Program II (ESSP II) Working Paper 23 Addis Ababa: International Food Policy Research Institute. 2011.

[25] BoFED RID. Oromiya National Regional State In Brief. Part V. 2014.

[26] Institute EHaNR. MASTER PLAN FOR THE PUBLIC HEALTH LABORATORY SYSTEM IN ETHIOPIA. Second Edition. (2009-2013).

[27] Mekasha A, Gerard B, Tesfaye K, Nigatu L, Duncan AJ. Interconnection between land use/land cover change and herders'/faimers' livestock feed resource management strategies: a case study from three Ethiopian eco-environments. Agriculture, Ecosystems \& Environment. 2014; 188: 150-62.

[28] Mustalahti K, Catassi C, Reunanen A, Fabiani E, Heier M, McMillan S, et al. The prevalence of celiac disease in Europe: results of a centralized, international mass screening project. Ann Med. 2010; 42(8): 587-95.

[29] Rubio-Tapia A, Ludvigsson JF, Brantner TL, Murray JA, Everhart JE. The prevalence of celiac disease in the United States. Am J Gastroenterol. 2012; 107(10): 1538-44; quiz 7, 45.

[30] Kelly CP, Bai JC, Liu E, Leffler DA. Advances in diagnosis and management of celiac disease. Gastroenterology. 2015; 148(6): 1175-86.

[31] Brusca I. Overview of biomarkers for diagnosis and monitoring of celiac disease. Adv Clin Chem. 2015; 68: 1-55.

[32] Naheed Anjum PNB, Nicola J Robinson and John D Aplin. Maternal celiac disease autoantibodies bind directly to syncytiotrophoblast and inhibit placental tissue transglutaminase activity. Reproductive Biology and Endocrinology. 2009; 7(16).

[33] Andren Aronsson C, Lee HS, Hard Af Segerstad EM, Uusitalo U, Yang J, Koletzko S, et al. Association of Gluten Intake During the First 5 Years of Life With Incidence of Celiac Disease Autoimmunity and Celiac Disease Among Children at Increased Risk. JAMA. 2019; 322(6): 514-23.

[34] Rostom A, Murray JA, Kagnoff MF. American Gastroenterological Association (AGA) Institute technical review on the diagnosis and management of celiac disease. Gastroenterology. 2006; 131(6): 1981-2002.

[35] Hill ID, Fasano A, Guandalini S, Hoffenberg E, Levy J, Reilly N, et al. NASPGHAN Clinical Report on the Diagnosis and Treatment of Gluten-related Disorders. J Pediatr Gastroenterol Nutr. 2016; 63(1): 156-65.

[36] Aarsland SJ, Castellanos-Gonzalez A, Lockamy KP, MuluDroppers R, Mulu M, White AC, et al. Treatable bacterial infections are underrecognized causes of fever in Ethiopian children. Am J Trop Med Hyg. 2012; 87(1): 128-33.

[37] Amah-Tariah FS, Olorunfemi OJ, Osunwoke EA. Serum Immunoglobulin Changes in Pregnancy Complicated with PreEclampsia and Diabetes in Nigerian Women. IOSR Journal of Dental and Medical Sciences (IOSR-JDMS). 2016; 15(7): 88.

[38] Jena Abel, Jona Conklin, Stephen K. Hunter, Ryan Empey, Eric Tyler, Ashley Christensen, et al. Defining normal IgG changes throughout pregnancy. Proceedings in Obstetrics and Gynecology. 2013; 3(2): 8 . 